1

2

3

4

5

6

17. Keywords: phytoremediation; plant growth promotion; mobilization; microbial inoculation;

\section{Microbial associated plant growth and heavy metal accumulation to improve}

\section{phytoextraction of contaminated soils}

\author{
Jennifer L. Wood ${ }^{l}$, Caixian Tang ${ }^{2}$ Ashley E. Franks ${ }^{1} *$
}

${ }^{1}$ Department of Physiology, Anatomy and Microbiology, La Trobe University, Melbourne

Campus, Victoria, 3086, Australia

${ }^{2}$ Department of Animal, Plant and Soil Sciences, Centre for AgriBiosciences, La Trobe

University, Melbourne Campus, Victoria, 3086, Australia

Assoc. Prof Ashley Franks (Corresponding author)

Dept. of Microbiology

La Trobe University, Melbourne, Victoria, 3086, Australia

Phone: +61 394792206

Mobile: 0477169590

Fax: + 6194791222

Email: A.Franks@1atrobe.edu.au

18 beneficial microorganisms

19 
21 Utilizing plants to remediate heavy metal contaminated soils, a process known as

22 phytoextraction, offers many advantages but has yet to reach levels of efficiency that would

23 make the strategy economically viable. Inoculation of the plant rhizosphere with microorganisms

24 is an established route to improving phytoextraction efficiency. In general, microorganisms can

25 improve phytoextraction by increasing the availability of heavy metals to the plant and by

26 increasing plant biomass. This review uses a meta-analysis of the results from 103 microbial-

27 augmented phytoextraction studies to examine if one of these microbial mechanisms has a

28 greater potential to positively impact phytoextraction. Trends surrounding the use of heavy

29 metal-accumulating versus non-heavy-metal-accumulating plants in phytoextraction are

30 discussed. Microbially induced improvements in the accumulation of heavy metals in plant

31 biomass, a focus of several studies, are always coincident with enhanced net phytoextraction.

32 However, microbial treatments that improved plant biomass are more prevalent in the literature

33 and account for a larger number of studies that reported improved phytoextraction, particularly in

34 non-heavy-metal-accumulating plants. The experimental findings emerging from the literature

35 that implicate specific microbial processes in improving phytoextraction are briefly reviewed and

36 used to underline trends observed from the meta-analysis that indicate future directions regarding

37 the use of microorganisms to improve phytoextraction efficiency. 
42 Phytoextraction, is a low-cost, environmentally friendly remediation technique that utilizes

43 specialized metal-accumulating plants, known as heavy metal hyperaccumulators (HMHs), or

44 metal-tolerant high biomass plants (non-HMH) to extract heavy metals from contaminated soils

45 (Vamerali et al. 2010). In contrast to traditional heavy-metal remediation strategies, which

46 involve the physical removal of contaminated soil, chemical washing and reburial, it is estimated

47 that phytoextraction could reduce operational costs as much as 30 -fold and reduce environmental

48 harm (Gerhardt et al. 2009). While holding considerable promise, phytoextraction is not

49 sufficiently efficient to be considered economically viable.

50 A frequently utilized strategy to improve phytoextraction is the inoculation of beneficial

51 microorganisms into the plant rhizosphere (Abhilash et al. 2012, Sessitsch et al. 2013). Microbial

52 candidates that improve heavy-metal phytoextraction are commonly sourced from contaminated

53 soils and microbial communities present at the plant root-soil interface (rhizosphere

54 communities) (Lodewyckx et al. 2002, Park et al. 2011, Zhang et al. 2011). These communities

55 are metabolically and taxonomically diverse, containing microorganisms that are pre-adapted to

56 conditions in situ and are capable of performing metabolic activities that can alter heavy metal-

57 bioavailability and promote plant growth (Bai et al. 2014, Dell'Amico et al. 2008, Ma et al. 2009,

58 Sumi et al. 2014). To date, multiple studies have evidenced that the addition of microorganisms

59 to the plant rhizosphere can improve heavy metal accumulation in plants (Abou-Shanab et al.

60 2003, Abou-Shanab et al. 2003, Amprayn et al. 2012, De Souza et al. 1999, Ma et al. 2013,

61 Malekzadeh et al. 2012, Whiting et al. 2001). 
62 There are multiple mechanisms by which microorganisms may improve the accumulation of

63 heavy metals in plants and hence phytoextraction. Broadly, these mechanisms assist

64 phytoextraction by increasing the bioavailability of heavy metals in the soil and/or promoting

65 plant growth (Abhilash et al. 2012, Mulligan 2005, Sessitsch et al. 2013), whereas increased

66 metal bioavailability can facilitate plant uptake and increase the concentration of heavy metals in

67 plant tissue, and plant-growth-promotion increases the amount of heavy metal-containing

68 biomass. The total amount of heavy metal extracted is a product of both concentration and

69 biomass production. Among the phytoextraction studies, there is often a trade-off between the 70 concentrations of heavy metals that plants can tolerate and the biomass produced (i.e., HMHs 71 versus non-HMHs).

72 The purpose of this review is to examine emerging trends and evidence from the literature 73 regarding how microorganisms may be assisting phytoextraction. We summarize and discuss the 74 outcomes of 103 microbial-augmented phytoextraction studies from approximately the last 75 decade to assess broadly which microbial mechanisms have the greatest potential to further 76 develop phytoextraction and whether HMHs or non-HMHs will best facilitate these advances. In 77 addition to discussing broadly microbial metal-mobilization and plant growth promotion (PGP) 78 to improve phytoextraction, we discuss cases from the literature that highlight the role of specific 79 microbial processes in improving phytoextraction in light of trends observed in the meta80 analysis.

81 2. Trends in phytoextraction research: microbial activities hypothesized to improve 82 phytoextraction 
83 To examine how microorganisms improve phytoextraction and trends in successful outcomes,

84 we performed a meta-analysis of 28 phytoextraction papers containing a total of 103 individual 85 phytoextraction studies utilizing either heavy metal hyperaccumulating plants (HMHs) or fast86 growing high biomass plant species (non-HMHs). Studies are defined in this report as 87 experiments that vary in plant species, microbial treatment or heavy metal application. For each 88 study, the effect of microbial inoculation on plant biomass (PB), concentration of heavy metal 89 per unit of plant tissue ([HM]), and net heavy metal extracted per plant $\left(\mathrm{HM}_{\text {net }}\right)$ was calculated 90 from the difference between the microbially treated and control samples as a percentage of the 91 control, as previously described (Kloepper et al. 1989) using the following equation:

93 The studies were grouped based on the response, of PB- and [HM]- parameters to microbial 94 inoculation. The change in $\mathrm{HM}_{\text {net }}$ due to microbial inoculation was used as a measure to indicate 95 the success of the microbial treatments in improving phytoextraction.

96 Over one quarter of the studies reported improvements in phytoextraction $\left(\mathrm{HM}_{\mathrm{net}}\right)$ through 97 improvements in both [HM] and PB following microbial inoculation. An increase in $\mathrm{HM}_{\text {net }}$ was 98 reported in all cases where microbial treatments increased $[\mathrm{HM}]$, even when PB was not affected 99 (Figure 1).

100 Although increases in [HM] were always associated with improvements in $\mathrm{HM}_{\text {net }}$, the percentage 101 of studies that reported microbial-induced increases in [HM] was considerably lower (35\%) than 102 the percentage of studies that reported microbial-induced increases in PB (70\%). 
Of the studies that reported increases in $\mathrm{HM}_{\text {net }}, 39 \%$ reported improvements in both $\mathrm{PB}$ and $104[\mathrm{HM}], 43 \%$ reported improvements in $\mathrm{PB}$ alone, while only $11 \%$ were able to be attributed to 105 improvements in [HM]. Thus, given the current data, compared to improvements in [HM], 106 improvements in $\mathrm{HM}_{\text {net }}$ are 1.6 times as likely to be associated with plant-growth promotion. By 107 comparing the scenarios whereby improvements in $\mathrm{HM}_{\text {net }}$ could be attributed to either $\mathrm{PB}$ or $108[\mathrm{HM}]$, we observe that improvements in $\mathrm{HM}_{\text {net }}$ are 3.9 times as likely to be reported as associated 109 with improvements in PB compared to [HM].

110 Thirty-five studies included in this meta-analysis used HMHs with no historical agricultural use, 111 and among these were the model HMHs, Noccaea caerulescens and Alyssum murale (Table 1). 112 Most studies (66) used high biomass agriculturally developed species, some of which have been 113 shown to hyperaccumulate metals under contaminated conditions, but are not HMHs, as 114 ultimately such conditions are toxic to the plant (van der Ent et al. 2015). Two studies used 115 species which are neither HMHs nor have a history of agricultural use, but have been reported as 116 agricultural weeds (Table 1; (Mitich 1996)).

117 Figure 2 shows the association of improvements in $\mathrm{HM}_{\text {net }}$ with improvements in $\mathrm{PB}$ or [HM] for 118 HMHs and non-HMHs. Improvements in $[\mathrm{HM}]$ were associated with HMHs and non-HMHs at 119 roughly the same frequency in this meta-analysis. However, improvements in PB were more 120 frequently associated with non-HMHs. Of the successful cases using non-HMHs, 50\% were due 121 to improvements in $\mathrm{PB}$ alone, $8 \%$ were due to an increase in [HM] and $38 \%$ to a combination of $122 \mathrm{~PB}$ and [HM] (Figure 2).

123 HMHs actively sequester and store heavy metals in their aerial tissues and are able to obtain 124 concentrations of heavy metals in their tissues 100-1000 times higher than concentrations found 
125 in non-accumulator plants (Alford et al. 2010, Rascio and Navari-Izzo 2011, van der Ent et al. 126 2013). However, HMHs have a number of properties that are not conducive to applied 127 phytoextraction. Many HMHs tend to be slow growing with shallow root systems that are 128 insufficient at permeating contaminated soils and extracting heavy metals to any great depth 129 (Brewer et al. 1999, Krämer 2005, Słomka et al. 2012). When we examined the net amount of 130 metals extracted per plant in individual studies, we found that non-HMHs generally extracted 131 more heavy metals (mg/plant) than HMHs, particularly for $\mathrm{Cd}$ and $\mathrm{Ni}$ (Figure 3). Compared to 132 non-HMHs, these trends most likely reflect the small size and slow growth of many HMHs. To 133 account for the variation in the duration of plant-growth experiments (ranging from 14 to 150 134 days), we also calculate the rate of metal extracted per plant per day. Largely, the trends 135 observed for total metal extracted were conserved when the duration of phytoextraction trials 136 were accounted for. These data suggest that despite the high foliar concentration of metals that 137 HMHs achieve, non-HMHs with high biomass production may be a more appropriate choice for 138 developing phytoextraction in the immediate future. Additionally, the growth habits of many 139 well-studied HMHs, such as the rosette form of Noccaea caerulescens, are not amenable to 140 mechanical harvesting, which would increase the cost of phytoextraction (Brewer et al. 1999). 141 However, HMH research will remain paramount for further understanding the uptake and 142 sequestration of heavy metals. Conceivably, the knowledge gained by unravelling how these 143 plants sequester such high concentrations of toxic metals will assist in the refinement of 144 phytoextraction in the future.

145 The observation that non-HMHs tend to extract larger quantities of heavy metals per plant than 146 HMHs and the high frequency of improved phytoextraction via PGP indicate that non-HMHs 147 may be an appropriate choice of plant for improving phytoextraction and microbial PGP (as 
opposed to microbial mobilization of heavy metals) may be a superior strategy for improving

149 phytoextraction. A point to be considered, though, is that usually only positive findings are 150 routinely published, which may have skewed the outcome for this meta-analysis. The combined 151 use of these two strategies is supported by the observed high frequency of microbial PGP in 152 conjunction with non-HMHs (Figure 2). However, it is noteworthy that improvements in [HM]

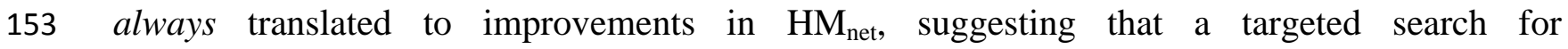
154 microorganisms that increase [HM], rather than improve plant biomass, is also a worthy research 155 direction.

\section{Linking Microbial Processes to Improvements in Phytoextraction}

\section{$157 \quad 3.1$ Microbial improvement of phytoextraction}

158 Multiple microbial processes exist that can stimulate plant growth or increase heavy metal 159 bioavailability or both. Detailed reviews on how microbial processes affect phytoextraction can 160 be found elsewhere (Abhilash et al. 2012, Lebeau et al. 2008, Mulligan 2005, Sessitsch et al. 161 2013). The following discussion highlights the experimental evidence emerging from the 162 literature that implicates specific microbial processes in improving phytoextraction and how they 163 relate to the trends observed in the meta-analysis. In an experimental setting, specific microbial 164 processes can rarely be identified, as the causative agent behind microbial-induced 165 improvements in phytoextraction, even when the PGP and/or metal-mobilizing ability of an 166 inoculum is known. This uncertainty is due to confounding factors, such as indigenous 167 microorganisms and soil physicochemistry, that make it difficult to determine the processes 168 being carried out by the inoculum in situ. As such, we will limit our discussion to work where a 169 strong cause and effect can be established between a specific microbial process and improved 170 phytoextraction. 
173 To solubilize inorganic phosphates $(\mathrm{P})$, microorganisms can produce and secrete an array of 174 organic acids, such as gluconic acid, 2-ketogluconic acid, lactic acid and acetic acid (Rodríguez 175 and Fraga 1999). The associated decrease in soil pH can also increase the solubility of some 176 heavy metals (Kim et al. 2013). Thus, P-solubilizing microorganisms are believed to increase 177 plant biomass by supporting plant health and mobilize heavy metals making them an attractive 178 strategy for improving phytoextraction.

179 Correlations between increased plant $\mathrm{P}$ uptake and increased plant biomass have been observed 180 under $\mathrm{Cu}$ stress following inoculation with the endophyte, Penicillium funiculosum (Khan and 181 Lee 2013). The endophyte has previously been reported as having P-solubilization activity and is 182 able to alleviate plant stress responses to $\mathrm{Cu}$ contamination, possibly via the secretion of 183 gibberellins. Despite the increase in plant biomass, the inoculum decreased $\mathrm{Cu}$ concentration in 184 the plant. A reduction in the amount of $\mathrm{Cu}$ accumulated in plant roots, in the presence of the 185 endophyte, suggested that free metal ions were being absorbed by the fungus, rather than being 186 transported into the plant (Khan and Lee 2013).

187 Improvements in phytoextraction due to the PGP ability of P-solubilizing microorganisms have 188 been demonstrated in experiments that decoupled the PGP and metal-mobilizing activity of a P189 solubilizing Burkholderia cepacia using a hydroponic experimental design in which heavy 190 metals are necessarily mobile ( $\mathrm{Li}$ et al. 2007). Using the $\mathrm{Cd} / \mathrm{Zn}$ hyperaccumulator, Sedum

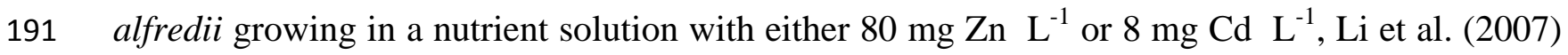
192 reported an increase in plant biomass that correlated with an increase in $\mathrm{P}$ uptake in the plants. 193 The microbial treatment had negligible or negative effects on the concentrations of $\mathrm{Zn}$ and $\mathrm{Cd}$ in 
194 the plants, but due to the increased biomass, the total amount of $\mathrm{Zn}$ and $\mathrm{Cd}$ extracted was 195 increased by $116 \%$ and 46\%, respectively (Li et al. 2007).

196 P-solubilizing microorganisms that improve phytoextraction by increasing both PGP and heavy 197 metal-mobilization have been reported. Compared to un-inoculated controls, the inoculation of 198 Brassica juncea with a P-solubilizing Bacillus spp. induced a 349\% increase in plant dry weight 199 after 8 weeks and a 148\% increase in Cd concentration (Jeong et al. 2013). However, reported 200 increases in IAA content in the soil and the presence of a native soil microbial community make 201 it difficult to attribute the experimental outcomes to P-solubilization alone.

202 Where organic acids improve $\mathrm{P}$ acquisition, microbial siderophores chelate and solubilize $\mathrm{Fe}^{3+}$ in 203 soil and improve iron acquisition by plants (Rajkumar et al. 2010). The mobilization of toxic 204 heavy metals by siderophores has also been demonstrated using the microbial siderophore 205 desferrioxamine-B (DFO-B). In the presence of $10 \mu \mathrm{M}$ Cd, DFO-B, the application improved Cd 206 accumulation in Noccaea caerulescens by $37 \%$ and increased root to shoot translocation by $27 \%$ 207 (Karimzadeh et al. 2012).

208 Evidence that siderophores produced by microorganisms in situ mobilize heavy metals and 209 improve phytoextraction comes from studies investigating $\mathrm{Zn}$ accumulation in $N$. caerulescens. 210 The addition of active rhizosphere communities to $N$. caerulescens affected a 4-fold increase in 211 net Zn hyperaccumulation due to the microbial mobilization of non-labile Zn pools (Whiting et 212 al. 2001). The increase in net $\mathrm{Zn}$ accumulation was a product of increases in plant biomass and 213 Zn concentration. Following a lack of evidence to support Zn mobilization via mechanisms that 214 alter soil $\mathrm{pH}$ (such as organic acid production), it was concluded that siderophores were most 215 likely responsible for the increase in labile $\mathrm{Zn}$. 
216 Even though the secretion of siderophores is a clear strategy for improving plant growth in iron-

217 limiting situations, there is little evidence of their ability to improve plant growth in the presence

218 of other heavy metals. The increases in $\mathrm{Cd}$ concentration in the aforementioned DFO-B

219 treatment were not linked to improvements in plant growth; the inoculum that increased $N$.

220 caerulescens biomass may have had additional PGP activities that were not measured

221 (Karimzadeh et al. 2012, Whiting et al. 2001).

222

2233.3 Improving plant nutrition to enhance phytoextraction: $\mathrm{N}_{2}$ fixation

224 Microbial-induced increases in plant nitrogen $(\mathrm{N})$ availability have also been linked to 225 improvements in phytoextraction. In pot trials, a heavy metal resistant, $\mathrm{N}_{2}$-fixing 226 Bradyrhizobium sp. (vigna), RN8 was able to increase the dry weight of green gram (Vigna 227 radiata L. wilczek) by $28 \%$ in a soil containing $9,780 \mathrm{mg} \mathrm{Zn} \mathrm{kg}^{-1}$ and by $24 \%$ in a soil containing $228580 \mathrm{mg} \mathrm{Ni} \mathrm{kg}{ }^{-1}$. Compared to un-inoculated controls, the increases in plant biomass were 229 accompanied by increases in total $\mathrm{N}$ content in the plant (Wani et al. 2007). Similar to the study 230 by $\mathrm{Li}$ et al. (2007) using P-solubilizing bacteria and Sedum alfredii, RN8 decreased 231 concentrations of $\mathrm{Zn}$ and $\mathrm{Ni}$ in shoots of green gram. However, in both cases the increase in 232 plant biomass created a net positive contribution to the total amount of heavy metals extracted 233 per plant (Li et al. 2007, Wani et al. 2007).

\subsection{Other microbial mechanisms of plant growth promotion to improve phytoextraction}

236 In addition to increasing plant growth by improving plant nutrition, microorganisms can improve 237 plant growth directly via the production of hormones, such as auxins (indole-3-acetic acid; IAA), 238 cytokinins and gibberellins or indirectly via stress inhibiting enzymes, such as 1- 

254 2010). phytoextraction. Non-biological methods of increasing plant growth, such as fertilizer

aminocyclopropane-1-carboxylic acid (ACC)-deaminase (Badri et al. 2009, García de Salamone et al. 2001, Glick 2003, Usha Rani et al. 2011). In plants, the expression of IAA-producing genes can be negatively regulated by the presence of heavy metals, such as $\mathrm{Cd}^{2+}$ (Elobeid et al. 2012). The microbial secretion of IAA can counteract the inhibitory effects of heavy metals on plant IAA production, enabling sustained plant growth (Elobeid et al. 2012). The direct relationship between microbial IAA production and improved plant growth, in the absence of heavy metals, has been demonstrated using Azospirillum brasilense strain SM and its IAA over- and underexpressing mutants (Kochar and Srivastava 2012). Although the microbial production of IAA has been repeatedly cited in the literature as a major factor contributing to hyperaccumulation of heavy metals via PGP, the presence of other PGP-processes makes it difficult to clearly establish cause and effect (Glick 2010, Lampis et al. 2015, Ma et al. 2011, Ma et al. 2009). Microbial use of IAA as a carbon source is an additional confounding factor in establishing whether IAA produced by an inoculum influences plant growth (Duca et al. 2014). Nevertheless, multiple reports demonstrated that foliar application of IAA or other phytohormones can improve the phytoextraction of metals, including $\mathrm{Ni}, \mathrm{Pb}$ and $\mathrm{Cd}$ (Cabello-Conejo et al. 2014, Hadi et al.

\subsection{The potential of improved plant biomass in enhancing phytoextraction}

The evidence that improved plant nutrition ( $\mathrm{P}$ or $\mathrm{N}$ ) increases phytoextraction by improving plant biomass, even when concentrations of heavy metals in plant tissues are reduced, lends weight to the notion of targeting PGP strategies over metal-mobilization strategies to improve application, have been shown to improve Ni extraction in Alyssum bertolonii by increasing plant 
262 biomass as much as $300 \%$ with no appreciable reduction in Ni concentration (Robinson et al.

263 1997). There are also numerous examples in the literature of PGP-microorganisms improving

264 phytoextraction, even if the mechanism of PGP action cannot be identified (Belimov et al. 2004,

265 He et al. 2009, Li et al. 2007, Liu et al. 2015, Ma et al. 2009, Malekzadeh et al. 2012, Rani et al.

266 2013). For instance, increases in canola biomass caused by inoculation of Pseudomonas

267 fluorescens and P. tolaasii increased total $\mathrm{Cd}$ accumulation by $72 \%$ and $107 \%$, respectively,

268 despite Cd concentrations in plant tissues remaining constant (Dell'Amico et al. 2008). Similarly,

269 increases in Salix dasyclados biomass following inoculation with the ectomycorrhizal fungi,

270 Amanita muscaria, increased total $\mathrm{Pb}$ accumulation by $85 \%$ without increasing $\mathrm{Pb}$ concentrations

271 in plant tissues (Hrynkiewicz and Baum 2013).

272

273 The contrasting ways in which PGP-microorganisms and heavy-metal-solubilizing

274 microorganisms improve heavy-metal accumulation were highlighted in research by Ma et al.

275 (2009a). The work used three microbial strains that improved Ni phytoextraction by Brassica

276 juncea in opposing ways. Two stains, SRA1 and SRA10 exhibited the high rates of siderophore

277 production (hydroxamate and catechol type) and P-solubilization, and the ability to mobilize Ni

278 in the soil, whilst a third strain, SRA2, exhibited the highest levels of IAA production and

279 possessed other PGP attributes. The opposing biochemical attributes of the two groups of 280 microorganisms corresponded well with the manner in which they influenced plant growth: The 281 metal-mobilizing strains elicited minor significant improvements in plant growth, but 282 considerably increased plant $\mathrm{Ni}$ concentration. Conversely, SRA2 had no impact on $\mathrm{Ni}$ 283 concentration but improved plant biomass by $285 \%$ (Ma et al. 2009). Surprisingly, the net 284 increase in $\mathrm{Ni}$ removed per plant (i.e., phytoextraction ability) was highest in the SRA2 
treatment. Although both SRA1 and SRA10 improved plant biomass and Ni concentration, 286 resulting in increases in net $\mathrm{Ni}$ extraction of $76 \%$ and $122 \%$, respectively, the large 287 improvements in plant biomass alone, caused by SRA2, which exhibited the highest levels of 288 IAA production, improved total Ni extraction by 388\% (Ma et al. 2009).

289 The observation that improved plant growth alone can be more effective at improving 290 phytoextraction than a combination of plant growth and metal mobilization reinforces the notion 291 that attempts to improve plant growth, as opposed to plant heavy metal-concentrations, are likely 292 to have a more significant impact on phytoremediation optimization in the immediate future. 293 However, combinations of metal-mobilization and PGP activities that work synergistically have 294 been reported and should also be considered.

\section{Conclusions and Future Perspectives}

297 Much is known regarding the avenues by which microorganisms are able to improve 298 phytoextraction efficiency. From the perspective of the plant, microorganisms can improve 299 phytoextraction by increasing plant biomass or by increasing the availability of heavy metals to 300 the plant. Our assessment of 103 phytoextraction studies indicates that the employment of 301 microbial mechanisms to improve plant biomass is more likely to lead to improvement of 302 phytoextraction and that these outcomes occur more frequently in association with non-HMH 303 plants. Closer inspection of the literature confirms that PGP microorganisms constitute a feasible 304 strategy for improving phytoextraction. The use of microorganisms to improve plant biomass via 305 improved $\mathrm{N}$ or $\mathrm{P}$ nutrition can have a significant positive impact on phytoextraction, even when heavy metal-concentration in the plant is unchanged. 
Microbial processes that mobilize heavy metals may not be the most efficient strategy for

308 improving phytoextraction on their own. However, there is substantial scope for research into the

309 use of metal-mobilization processes in a synergistic fashion with plant-growth promotion to 310 improve phytoextraction.

\section{Acknowledgments}

312 A. E. Franks and J.L. Wood received funding from the Defense Science Institute Synthetic 313 Biology Initiative. A.E. Franks receives funding from Australian Research Council Linkage 314 Project (LP140100459), Office of Naval Research Global (Award No N626909-13-1-N259) and 315 Asian Office of Aerospace Research and Development, (Award Number FA2386-14-1-4032). C. 316 Tang receives funding from an Australian Research Council Linkage Project (LP100100800).

317 References:

318 Abhilash, P. C., Powell, J. R., Singh, H. B. and Singh, B. K., 2012. Plant-microbe interactions:

319 Novel applications for exploitation in multipurpose remediation technologies. Trends in 320 Biotechnology 30, 416-420.

321 Abou-Shanab, R. A., Angle, J. S., Delorme, T. A., Chaney, R. L., Van Berkum, P., Moawad, H., 322 Ghanem, K. and Ghozlan, H. A., 2003. Rhizobacterial effects on nickel extraction from soil and 323 uptake by Alyssum murale. New Phytologist 158, 219-224.

324 Abou-Shanab, R. I., Delorme, T. A., Angle, J. S., Chaney, R. L., Ghanem, K., Moawad, H. and 325 Ghozlan, H. A., 2003. Phenotypic Characterization of Microbes in the Rhizosphere of Alyssum 326 murale. International Journal of Phytoremediation 5, 367-379.

327 Alford, É. R., Pilon-Smits, E. A. H. and Paschke, M. W., 2010. Metallophytes-a view from the 328 rhizosphere. Plant and Soil 337, 33-50. 
Amprayn, K. O., Rose, M. T., Kecskés, M., Pereg, L., Nguyen, H. T. and Kennedy, I. R., 2012. Plant growth promoting characteristics of soil yeast (Candida tropicalis HY) and its effectiveness for promoting rice growth. Applied Soil Ecology 61, 295-299.

Badri, D. V., Weir, T. L., van der Lelie, D. and Vivanco, J. M., 2009. Rhizosphere chemical dialogues: plant-microbe interactions. Current Opinion in Biotechnology 20, 642-650.

Bai, Y., Liang, J., Liu, R., Hu, C. and Qu, J., 2014. Metagenomic analysis reveals microbial diversity and function in the rhizosphere soil of a constructed wetland. Environmental Technology 35, 2521-2527.

Belimov, A. A., Kunakova, A. M., Safronova, V. I., Stepanok, V. V., Yudkin, L. Y., Alekseev, Y. V. and Kozhemyakov, A. P., 2004. Employment of rhizobacteria for the inoculation of barley plants cultivated in soil contaminated with lead and cadmium. Microbiology 73, 99-106.

Brewer, E. P., Saunders, J. A., Angle, J. S., Chaney, R. L. and McIntosh, M. S., 1999. Somatic hybridization between the zinc accumulator Thlaspi caerulescens and Brassica napus.

Theoretical and Applied Genetics 99, 761-771.

Cabello-Conejo, M. I., Prieto-Ferna'ndez, T. and Kidd, P. S., 2014. Exogenous treatments with phytohormones can improve growth and nickel yield of hyperaccumulating plants. Science of the Total Environment 494-495, 1-8.

De Souza, M. P., Huang, C. P. A., Chee, N. and Terry, N., 1999. Rhizosphere bacteria enhance the accumulation of selenium and mercury in wetland plants. Planta 209, 259-263.

Dell'Amico, E., Cavalca, L. and Andreoni, V., 2008. Improvement of Brassica napus growth under cadmium stress by cadmium-resistant rhizobacteria. Soil Biology and Biochemistry 40, 7484. 
Duca, D., Lorv, J., Patten, C. L., Rose, D. and Glick, B. R., 2014. Indole-3-acetic acid in plantmicrobe interactions. Antonie van Leeuwenhoek, International Journal of General and Molecular Microbiology 106, 85-125.

Elobeid, M., Göbel, C., Feussner, I. and Polle, A., 2012. Cadmium interferes with auxin physiology and lignification in poplar. Journal of Experimental Botany 63, 1413-1421.

García de Salamone, I. E., Hynes, R. K. and Nelson, L. M., 2001. Cytokinin production by plant growth promoting rhizobacteria and selected mutants. Canadian Journal of Microbiology 47, 404-411.

Gerhardt, K. E., Huang, X. D., Glick, B. R. and Greenberg, B. M., 2009. Phytoremediation and rhizoremediation of organic soil contaminants: Potential and challenges. Plant Science 176, 2030.

Glick, B. R., 2003. Phytoremediation: Synergistic use of plants and bacteria to clean up the environment. Biotechnology Advances 21, 383-393.

Glick, B. R., 2010. Using soil bacteria to facilitate phytoremediation. Biotechnology Advances $28,367-374$.

Hadi, F., Bano, A. and Fuller, M. P., 2010. The improved phytoextraction of lead $(\mathrm{Pb})$ and the growth of maize (Zea mays L.): The role of plant growth regulators (GA3 and IAA) and EDTA alone and in combinations. Chemosphere 80, 457-462.

He, L. Y., Chen, Z. J., Ren, G. D., Zhang, Y. F., Qian, M. and Sheng, X. F., 2009. Increased cadmium and lead uptake of a cadmium hyperaccumulator tomato by cadmium-resistant bacteria. Ecotoxicology and Environmental Safety 72, 1343-1348.

Hrynkiewicz, K. and Baum, C., 2013. Selection of ectomycorrhizal willow genotype in phytoextraction of heavy metals. Environmental Technology 34, 225-230. 
Jeong, S., Moon, H. S., Shin, D. and Nam, K., 2013. Survival of introduced phosphatesolubilizing bacteria (PSB) and their impact on microbial community structure during the phytoextraction of Cd-contaminated soil. Journal of Hazardous Materials 263, 441-449.

Karimzadeh, L., Heilmeier, H. and Merkel, B. J., 2012. Effect of microbial siderophore DFO-B on Cd accumulation by Thlaspi caerulescens hyperaccumulator in the presence of zeolite. Chemosphere 88, 683-687.

Khan, A. L. and Lee, I. J., 2013. Endophytic Penicillium funiculosum LHL06 secretes gibberellin that reprograms Glycine max L. growth during copper stress. BMC Plant Biology 13. Kim, J. O., Lee, Y. W. and Chung, J., 2013. The role of organic acids in the mobilization of heavy metals from soil. KSCE Journal of Civil Engineering 17, 1596-1602.

Kloepper, J. W., Ran L., and Zablotowicz, R. M., 1989. Free-living bacterial inocula for enhancing crop productivity. Trends in biotechnology 7, 39-44.

Kochar, M. and Srivastava, S., 2012. Surface colonization by Azospirillum brasilense SM in the indole-3-acetic acid dependent growth improvement of sorghum. Journal of Basic Microbiology $52,123-131$

Krämer, U., 2005. Phytoremediation: Novel approaches to cleaning up polluted soils. Current Opinion in Biotechnology 16, 133-141.

Lampis, S., Santi, C., Ciurli, A., Andreolli, M. and Vallini, G., 2015. Promotion of arsenic phytoextraction efficiency in the fern Pteris vittata by the inoculation of As-resistant bacteria: A soil bioremediation perspective. Frontiers in Plant Science 6.

Lebeau, T., Braud, A. and Jézéquel, K., 2008. Performance of bioaugmentation-assisted phytoextraction applied to metal contaminated soils: A review. Environmental Pollution 153, 497-522. 
Li, W. C., Ye, Z. H. and Wong, M. H., 2007. Effects of bacteria on enhanced metal uptake of the

398 Cd/Zn-hyperaccumulating plant, Sedum alfredii. Journal of Experimental Botany 58, 4173-4182.

399 Liu, W., Wang, Q., Wang, B., Hou, J., Luo, Y., Tang, C. and Franks, A. E., 2015. Plant growth-

400 promoting rhizobacteria enhance the growth and $\mathrm{Cd}$ uptake of Sedum plumbizincicola in a Cd-

401 contaminated soil. Journal of Soils and Sediments, 1-9.

402 Lodewyckx, C., Mergeay, M., Vangronsveld, J., Clijsters, H. and Van Der Lelie, D., 2002.

403 Isolation, characterization, and identification of bacteria associated with the zinc

404 hyperaccumulator Thlaspi caerulescens subsp. calaminaria. International Journal of

405 Phytoremediation 4, 101-115.

406 Ma, Y., Prasad, M. N. V., Rajkumar, M. and Freitas, H., 2011. Plant growth promoting

407 rhizobacteria and endophytes accelerate phytoremediation of metalliferous soils. Biotechnology

408 Advances 29, 248-258.

409 Ma, Y., Rajkumar, M. and Freitas, H., 2009. Improvement of plant growth and nickel uptake by

410 nickel resistant-plant-growth promoting bacteria. Journal of Hazardous Materials 166, 1154-

4111161.

412 Ma, Y., Rajkumar, M. and Freitas, H., 2009. Inoculation of plant growth promoting bacterium

413 Achromobacter xylosoxidans strain Ax10 for the improvement of copper phytoextraction by

414 Brassica juncea. Journal of Environmental Management 90, 831-837.

415 Ma, Y., Rajkumar, M., Luo, Y. and Freitas, H., 2013. Phytoextraction of heavy metal polluted

416 soils using Sedum plumbizincicola inoculated with metal mobilizing Phyllobacterium

417 myrsinacearum RC6b. Chemosphere 93, 1386-1392. 
418

419

420

421

422

423

424

425

426

427

428

429

430

431

432

433

434

435

436

437

438

439

440

Malekzadeh, E., Alikhani, H. A., Savaghebi-Firoozabadi, G. R. and Zarei, M., 2012.

Bioremediation of cadmium-contaminated soil through cultivation of maize inoculated with plant growth-promoting rhizobacteria. Bioremediation Journal 16, 204-211.

Mitich, L. W., 1996. Field pennycress (Thlaspi arvense L.) - The stinkweed. Weed Technology $10,675-678$.

Mulligan, C. N., 2005. Environmental applications for biosurfactants. Environmental Pollution $133,183-198$.

Park, J. H., Bolan, N., Megharaj, M. and Naidu, R., 2011. Isolation of phosphate solubilizing bacteria and their potential for lead immobilization in soil. Journal of Hazardous Materials 185, 829-836.

Rajkumar, M., Ae, N., Prasad, M. N. V. and Freitas, H., 2010. Potential of siderophoreproducing bacteria for improving heavy metal phytoextraction. Trends in Biotechnology 28, 142149.

Rani, A., Souche, Y. and Goel, R., 2013. Comparative in situ remediation potential of Pseudomonas putida 710A and Commamonas aquatica 710B using plant (Vigna radiata (L.) wilczek) assay. Annals of Microbiology 63, 923-928.

Rascio, N. and Navari-Izzo, F., 2011. Heavy metal hyperaccumulating plants: How and why do they do it? And what makes them so interesting? Plant Science 180, 169-181.

Robinson, B. H., Chiarucci, A., Brooks, R. R., Petit, D., Kirkman, J. H., Gregg, P. E. H. and De Dominicis, V., 1997. The nickel hyperaccumulator plant Alyssum bertolonii as a potential agent for phytoremediation and phytomining of nickel. Journal of Geochemical Exploration 59, 75-86.

Rodríguez, H. and Fraga, R., 1999. Phosphate solubilizing bacteria and their role in plant growth promotion. Biotechnology Advances 17, 319-339. 
441 Sessitsch, A., Kuffner, M., Kidd, P., Vangronsveld, J., Wenzel, W. W., Fallmann, K. and

442 Puschenreiter, M., 2013. The role of plant-associated bacteria in the mobilization and

443 phytoextraction of trace elements in contaminated soils. Soil Biology and Biochemistry 60, 182-

444194.

445 Słomka, A., Jedrzejczyk-Korycińska, M., Rostański, A., Karcz, J., Kawalec, P. and Kuta, E.,

446 2012. Heavy metals in soil affect reproductive processes more than morphological characters in

447 Viola tricolor. Environmental and Experimental Botany 75, 204-211.

448 Sumi, H., Kunito, T., Ishikawa, Y., Sato, T., Park, H. D., Nagaoka, K. and Aikawa, Y., 2014.

449 Plant roots influence microbial activities as well as cadmium and zinc fractions in metal-

450 contaminated soil. Chemistry and Ecology.

451 Usha Rani, M., Arundhathi and Reddy, G., 2011. Bacillus cereus and Enterobacter cancerogenus

452 screened for their efficient plant growth promoting traits rhizobacteria (PGPR) and antagonistic

453 traits among sixteen bacterial isolates from rhizospheric soils of Pigeon Pea. African Journal of

454 Microbiology Research 5, 2090-2094.

455 Vamerali, T., Bandiera, M. and Mosca, G., 2010. Field crops for phytoremediation of metal-

456 contaminated land. A review. Environmental Chemistry Letters 8, 1-17.

457 van der Ent, A., Baker, A. J. M., Reeves, R. D., Pollard, A. J. and Schat, H., 2013.

458 Hyperaccumulators of metal and metalloid trace elements: Facts and fiction. Plant and Soil 362,

$459 \quad 319-334$.

460 van der Ent, A., Baker, A. J. M., Reeves, R. D., Pollard, A. J. and Schat, H., 2015. Commentary:

461 Toward a more physiologically and evolutionarily relevant definition of metal

462 hyperaccumulation in plants. Frontiers in Plant Science 6, 554. 
$468 \quad 3150$.

469

470

471

472

473

$474 \quad$ Figures

475

476

477

478

479

480

481

482

483

484

Wani, P. A., Khan, M. S. and Zaidi, A., 2007. Effect of metal tolerant plant growth promoting Bradyrhizobium sp. (vigna) on growth, symbiosis, seed yield and metal uptake by greengram plants. Chemosphere 70, 36-45.

Whiting, S. N., De Souza, M. P. and Terry, N., 2001. Rhizosphere bacteria mobilize Zn for hyperaccumulation by Thlaspi caerulescens. Environmental Science \& Technology 35, 3144-

Zhang, Y. F., He, L. Y., Chen, Z. J., Wang, Q. Y., Qian, M. and Sheng, X. F., 2011.

Characterization of ACC deaminase-producing endophytic bacteria isolated from copper-tolerant plants and their potential in promoting the growth and copper accumulation of Brassica napus. Chemosphere 83, 57-62.

Figure 1. Summary of the main outcomes across all microbial-mediated phytoextraction studies. Studies are subdivided into six classes based on the behavior of the response variables plant biomass (PB)* and concentrations of heavy metal in plant tissues ([HM]). The behavior of the response variables was classified as increased $(\uparrow)$, decreased $(\downarrow)$ or unchanged (nil-). Within each response, variable-category studies were subdivided based on whether microbial treatments were successful (blues) or unsuccessful (oranges) at improving the net amount of heavy metals extracted $\left(\mathrm{HM}_{\mathrm{net}}\right)$ per plant (Abou-Shanab et al. 2006, Belimov et al. 2004, Dell'Amico et al. 2008, Gao et al. 2010, He et al. 2009, Jeong et al. 2013, Khan and Lee 2013, Lampis et al. 2015, Li et al. 2007, Liu et al. 2015, Ma et al. 2009, Ma et al. 2009, Ma et al. 2011, Ma et al. 2013, Malekzadeh et al. 2012, Marques et al. 2013, Płociniczak et al. 2013, Prapagdee et al. 2013, 
486 Xia 2006, Wani and Khan 2013, Wani et al. 2007, Whiting et al. 2001, Yang et al. 2012, Zaidi et 487 al. 2006, Zhang et al. 2012). *Wherever possible, dry plant biomass was used.

488 Figure 2. Association of increased heavy-metal extraction per plant $\left(\mathrm{HM}_{\mathrm{net}}\right)$ with increases in 489 plant biomass (PB; green), increases in concentrations of heavy metals in plant tissues ([HM];

490 blue) or both (overlap) for studies using heavy metal hyperaccumulating plants (HMH) and

491 studies using non-hyperaccumulating plants (non-HMH).

492 Figure 3. Distribution of heavy metals accumulated by heavy metal hyperaccumulators and non493 hyperaccumulators in microbial-augmented phytoextraction studies.

495 Table 1. Heavy metal hyperaccumulator $(\mathrm{HMH})$ and non-HMH plant species used in 496 phytoextraction studies included in the meta-analysis and the metals used in phytoextraction.

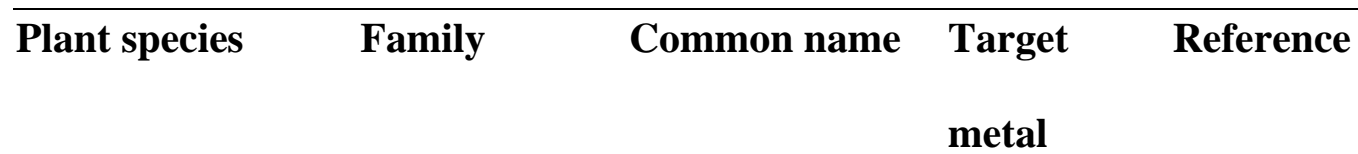

Heavy metal hyperaccumulator

\begin{tabular}{lllll}
\hline Alyssum murale & Brassicaceae & Yellowtuft & $\mathrm{Ni}$ & Abou-Shanab et al, 2006
\end{tabular}

Alyssum $\quad$ Brassicaceae $\quad$ Ni $\quad$ Ma et al, 2011

serpyllifolium

Noccaea Brassicaceae Alpine penny- $\quad$ Cd, $\mathrm{Zn} \quad$ Karimzadeh et al, 2012; 
caerulescens

Pteris vittata

Pteris vittata

Pteridaceae

Chinese brake

fern

As

Sedum alfredii Crassulaceae

$\mathrm{Cd}, \mathrm{Zn}$

Li et al, 2007; Zhang et al, 2012

Sedum Crassulaceae

plumbizincicola
Whiting et al, 2001

Lampis et al, 2015; Yang

et al, 2012
Cd, Pb, Zn Liu et al, 2014; Ma et al, 2013

Non-heavy metal hyperaccumulator

\begin{tabular}{|c|c|c|c|c|}
\hline Brassica juncea & Brassicaceae & Indian mustard & $\mathrm{Ni}, \mathrm{Cu}$ & $\begin{array}{l}\text { Rajkumar et al, 2013; Ma } \\
\text { et al, 2011, Ma et al, } \\
\text { 2009a; Zaidi et al, } 2006\end{array}$ \\
\hline Brassica napus & Brassicaceae & Canola & $\mathrm{Cd}$ & $\begin{array}{l}\text { Dell'Amico et al, 2008; } \\
\text { Sheng et at, 2006; Sheng et } \\
\text { at, } 2008\end{array}$ \\
\hline $\begin{array}{l}\text { Brassica } \\
\text { oxyrrhina* }\end{array}$ & Brassicaceae & $\begin{array}{l}\text { Smooth-stemmed } \\
\text { turnip }\end{array}$ & $\mathrm{Ni}$ & Ma et al. 2009a \\
\hline Glycine $\max$ & Fabaceae & Soybean & $\mathrm{Cu}$ & Khan \& Lee, 2013 \\
\hline Helianthus annuus & Asteraceae & Sunflower & $\mathrm{Cd}, \mathrm{Zn}$ & Marques et al, 2013; \\
\hline
\end{tabular}


Prapagdee et al, 2013

$\begin{array}{lllll}\text { Hordeum vulgare } & \text { Poaceae } & \text { Barley } & \mathrm{Cd}, \mathrm{Pb} & \text { Belimov et al, } 2004 \\ \text { Lens culinaris } & \text { Fabaceae } & \text { Lentil } & \mathrm{Ni} & \text { Wani \& Khan, 2013 } \\ \text { Luffa cylindrica } & \text { Cucurbitaceae } & \text { Sponge gourd } & \mathrm{Ni} & \text { Rajkumar et al, 2013 } \\ \text { Lycopersicon } & \text { Solanaceae } & \text { Tomato } & \mathrm{Cd}, \mathrm{Pb} & \mathrm{He} \text { et al, 2009; Sheng et al, } \\ \text { esculentum } & & & & 2008\end{array}$

Ricinus communis Euphorbiaceae Castor oil plant $\quad \mathrm{Cu}, \mathrm{Ni}, \mathrm{Zn} \quad$ Rajkumar \& Freitas, 2008

Sinapis alba Brassicaceae White mustard $\quad \mathrm{Cd}, \mathrm{Cu}, \mathrm{Zn} \quad$ Plociniczak et al, 2013

Solanum nigrum Solanaceae Black nightshade Cd Gao et al, 2010

Sorghum halepense Poaceae Sorghum $\quad$ Cd, Ni Rajkumar et al, 2013;

Sheng et at, 2008

Thlaspi arvense* $\quad$ Brassicaceae Field penny cress Zn Whiting et al, 2001

Vigna radiata Fabaceae $\quad$ Mung bean $\quad$ Cd, Ni, Zn Rani et al, 2013; Wani et

al, 2007

Zeamays $\quad$ Poaceae $\quad$ Corn $\quad$ Cd $\quad$ Malekzadeh et al, 2012;

Sheng et at, 2008

*agricultural weed 
499 Figure captions:

500 Figure 1. Summary of the main outcomes across all microbial-mediated phytoextraction studies.

501 Studies are subdivided into six classes based on the behavior of the response variables plant 502 biomass $(\mathrm{PB})^{*}$ and concentrations of heavy metal in plant tissues ([HM]). The behavior of the 503 response variables were classified as increased $(\uparrow)$, decreased $(\downarrow)$ or unchanged (nil-). Within 504 each response variable-category, studies were subdivided based on whether microbial treatments 505 were successful (blues) or unsuccessful (oranges) at improving the net amount of heavy metals 506 extracted $\left(\mathrm{HM}_{\text {net }}\right)$ per plant (Abou-Shanab et al. 2006, Belimov et al. 2004, Dell'Amico et al. 507 2008, Gao et al. 2010, He et al. 2009, Jeong et al. 2013, Khan and Lee 2013, Lampis et al. 2015, 508 Li et al. 2007, Liu et al. 2015, Ma et al. 2009, Ma et al. 2009, Ma et al. 2011, Ma et al. 2013, 509 Malekzadeh et al. 2012, Marques et al. 2013, Płociniczak et al. 2013, Prapagdee et al. 2013,

510 Rajkumar and Freitas 2008, Rajkumar et al. 2013, Rani et al. 2013, Sheng et al. 2008, Sheng and 511 Xia 2006, Wani and Khan 2013, Wani et al. 2007, Whiting et al. 2001, Yang et al. 2012, Zaidi et 512 al. 2006, Zhang et al. 2012). *Wherever possible, dry plant biomass was used.

515 Figure 2. Association of increased heavy metal extraction per plant $\left(\mathrm{HM}_{\mathrm{net}}\right)$ with increases in 516 plant biomass (PB; green), increases in concentrations of heavy metals in plant tissues ([HM];

517 blue) or both (overlap) for studies using heavy metal hyperaccumulating plants (HMH) and 518 studies using non-hyperaccumulating plants (non-HMH). 
520 Figure 3. Distribution of heavy metals accumulated by heavy metal hyperaccumulators and non521 hyperaccumulators in microbial-augmented phytoextraction studies.

522

523 
Table 1. Heavy metal hyperaccumulator (HMH) and non-HMH plant species used in phytoextraction studies included in the meta-analysis and the metals used in phytoextraction.

\begin{tabular}{|c|c|c|c|c|}
\hline Plant species & Family & Common name & Target & Reference \\
\hline
\end{tabular}

Heavy metal hyperaccumulator

\begin{tabular}{lllll}
\hline $\begin{array}{l}\text { Alyssum murale } \\
\text { Alyssum }\end{array}$ & Brassicaceae & Yellowtuft & $\mathrm{Ni}$ & Abou-Shanab et al, 2006 \\
serpyllifolium & Brassicaceae & & $\mathrm{Ni}$ & Ma et al, 2011 \\
Noccaea & Brassicaceae & Alpine penny- & $\mathrm{Cd}, \mathrm{Zn}$ & Karimzadeh et al, 2012; \\
caerulescens & & cress & & Whiting et al, 2001 \\
& & & & \\
Pteris vittata & Pteridaceae & Chinese brake & As & Lampis et al, 2015; Yang \\
& & fern & & et al, 2012
\end{tabular}

Sedum alfredii Crassulaceae Cd, Zn Li et al, 2007; Zhang et al, 2012

Sedum Crassulaceae Cd, Pb, Zn Liu et al, 2014; Ma et al, plumbizincicola 2013

Non-heavy metal hyperaccumulator

\begin{tabular}{|c|c|c|c|c|}
\hline Brassica juncea & Brassicaceae & Indian mustard & $\mathrm{Ni}, \mathrm{Cu}$ & Rajkumar et al, 2013; Ma \\
\hline
\end{tabular}




\begin{tabular}{|c|c|c|c|c|}
\hline Brassica napus & Brassicaceae & Canola & $\mathrm{Cd}$ & $\begin{array}{l}\text { Dell'Amico et al, 2008; } \\
\text { Sheng et at, 2006; Sheng et } \\
\text { at, } 2008\end{array}$ \\
\hline $\begin{array}{l}\text { Brassica } \\
\text { oxyrrhina* }\end{array}$ & Brassicaceae & $\begin{array}{l}\text { Smooth-stemmed } \\
\text { turnip }\end{array}$ & $\mathrm{Ni}$ & Ma et al. 2009a \\
\hline Glycine $\max$ & Fabaceae & Soybean & $\mathrm{Cu}$ & Khan \& Lee, 2013 \\
\hline Helianthus annuus & Asteraceae & Sunflower & $\mathrm{Cd}, \mathrm{Zn}$ & $\begin{array}{l}\text { Marques et al, 2013; } \\
\text { Prapagdee et al, } 2013\end{array}$ \\
\hline Hordeum vulgare & Poaceae & Barley & $\mathrm{Cd}, \mathrm{Pb}$ & Belimov et al, 2004 \\
\hline Lens culinaris & Fabaceae & Lentil & $\mathrm{Ni}$ & Wani \& Khan, 2013 \\
\hline Luffa cylindrica & Cucurbitaceae & Sponge gourd & $\mathrm{Ni}$ & Rajkumar et al, 2013 \\
\hline $\begin{array}{l}\text { Lycopersicon } \\
\text { esculentum }\end{array}$ & Solanaceae & Tomato & $\mathrm{Cd}, \mathrm{Pb}$ & $\begin{array}{l}\text { He et al, 2009; Sheng et al, } \\
2008\end{array}$ \\
\hline
\end{tabular}

Ricinus communis Euphorbiaceae Castor oil plant $\quad \mathrm{Cu}, \mathrm{Ni}, \mathrm{Zn} \quad$ Rajkumar \& Freitas, 2008

Sinapis alba Brassicaceae White mustard $\quad \mathrm{Cd}, \mathrm{Cu}, \mathrm{Zn} \quad$ Plociniczak et al, 2013

Solanum nigrum Solanaceae $\quad$ Black nightshade Cd Gao et al, 2010

Sorghum halepense Poaceae Sorghum Cd, Ni Rajkumar et al, 2013;

Sheng et at, 2008 
Thlaspi arvense* $^{*} \quad$ Brassicaceae Field penny cress Zn $\quad$ Whiting et al, 2001

Vigna radiata Fabaceae $\quad$ Mung bean $\quad$ Cd, Ni, Zn Rani et al, 2013; Wani et

al, 2007

Zeamays $\quad$ Poaceae $\quad$ Corn $\quad$ Cd $\quad$ Malekzadeh et al, 2012;

Sheng et at, 2008

*agricultural weed 


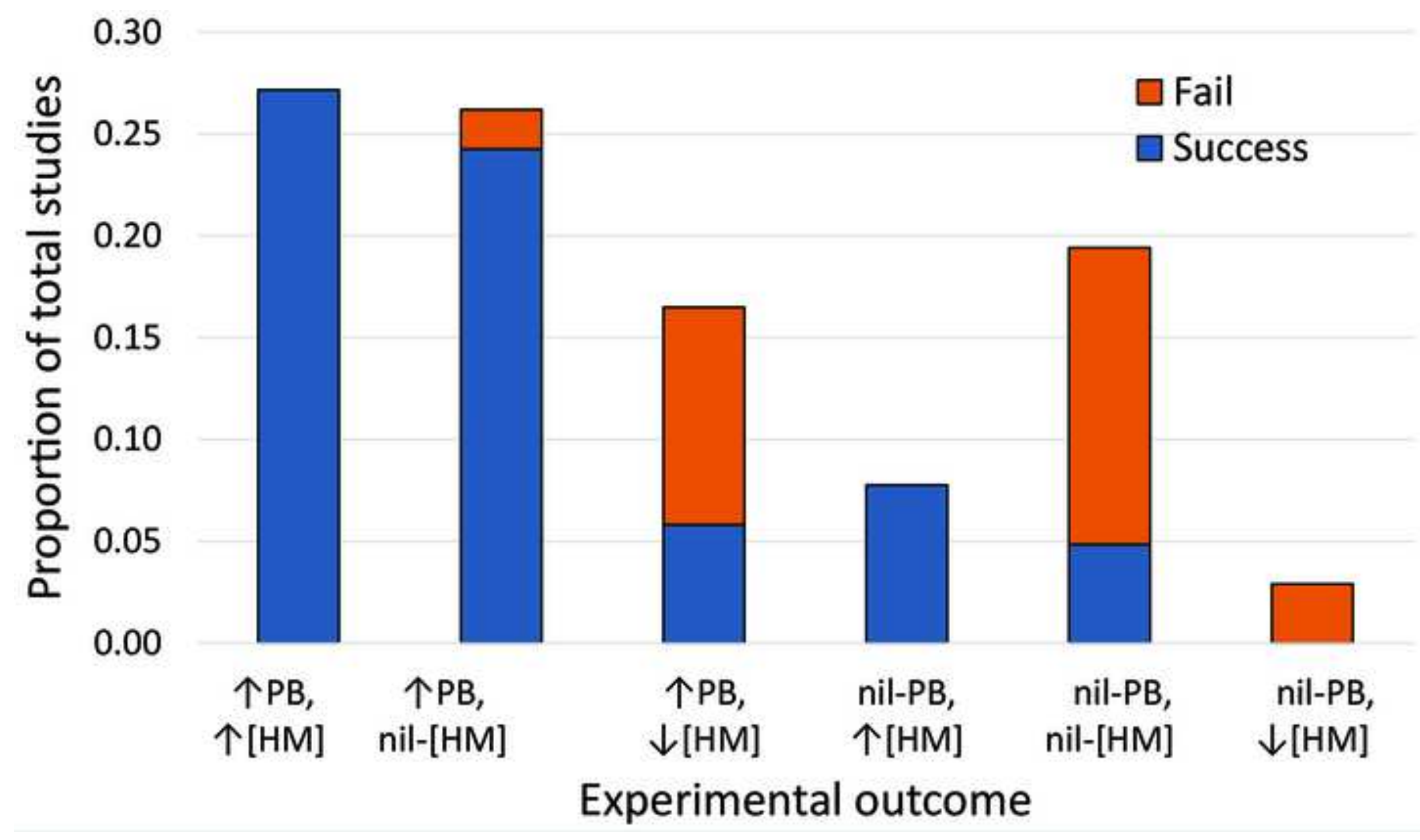




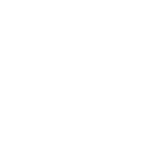

Studies using HMHs

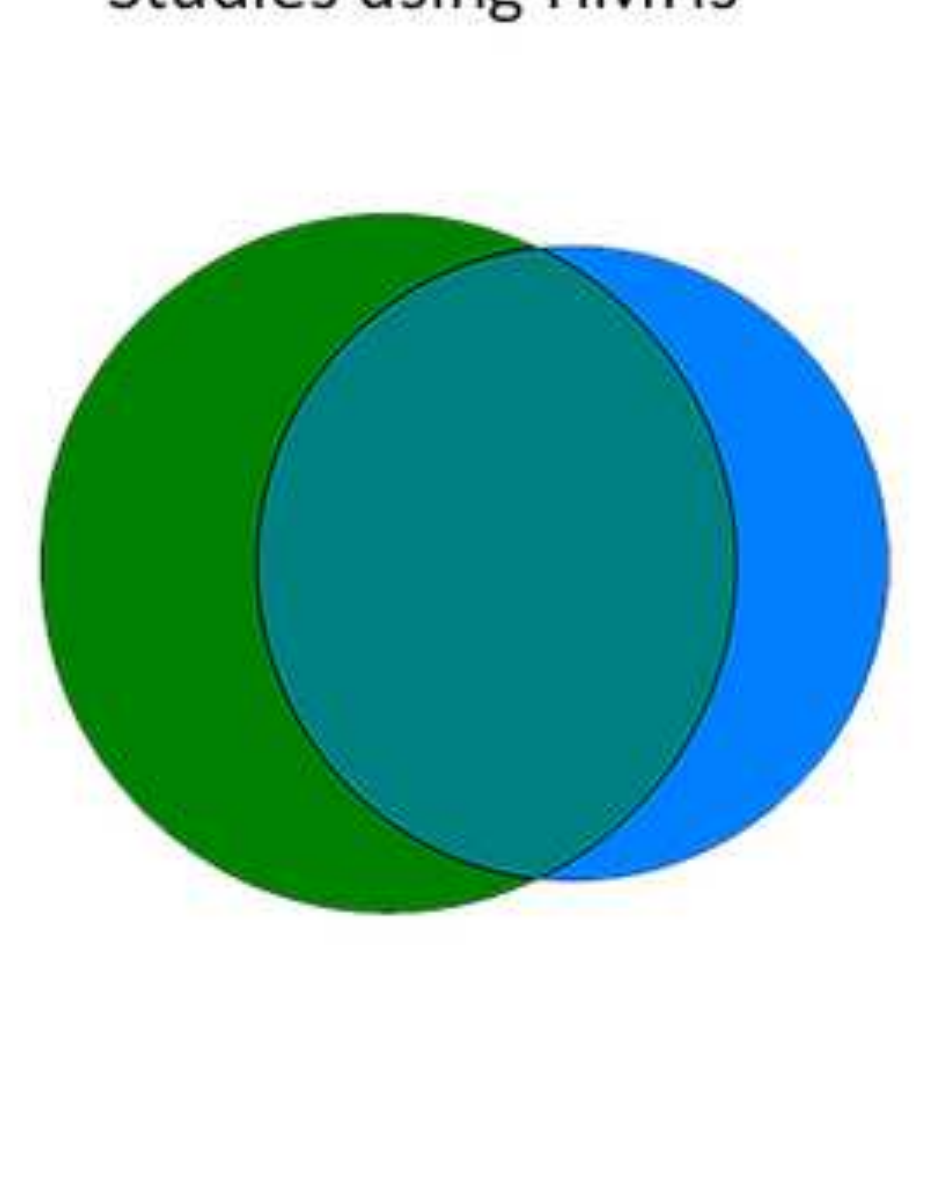

Studies using non-HMHs

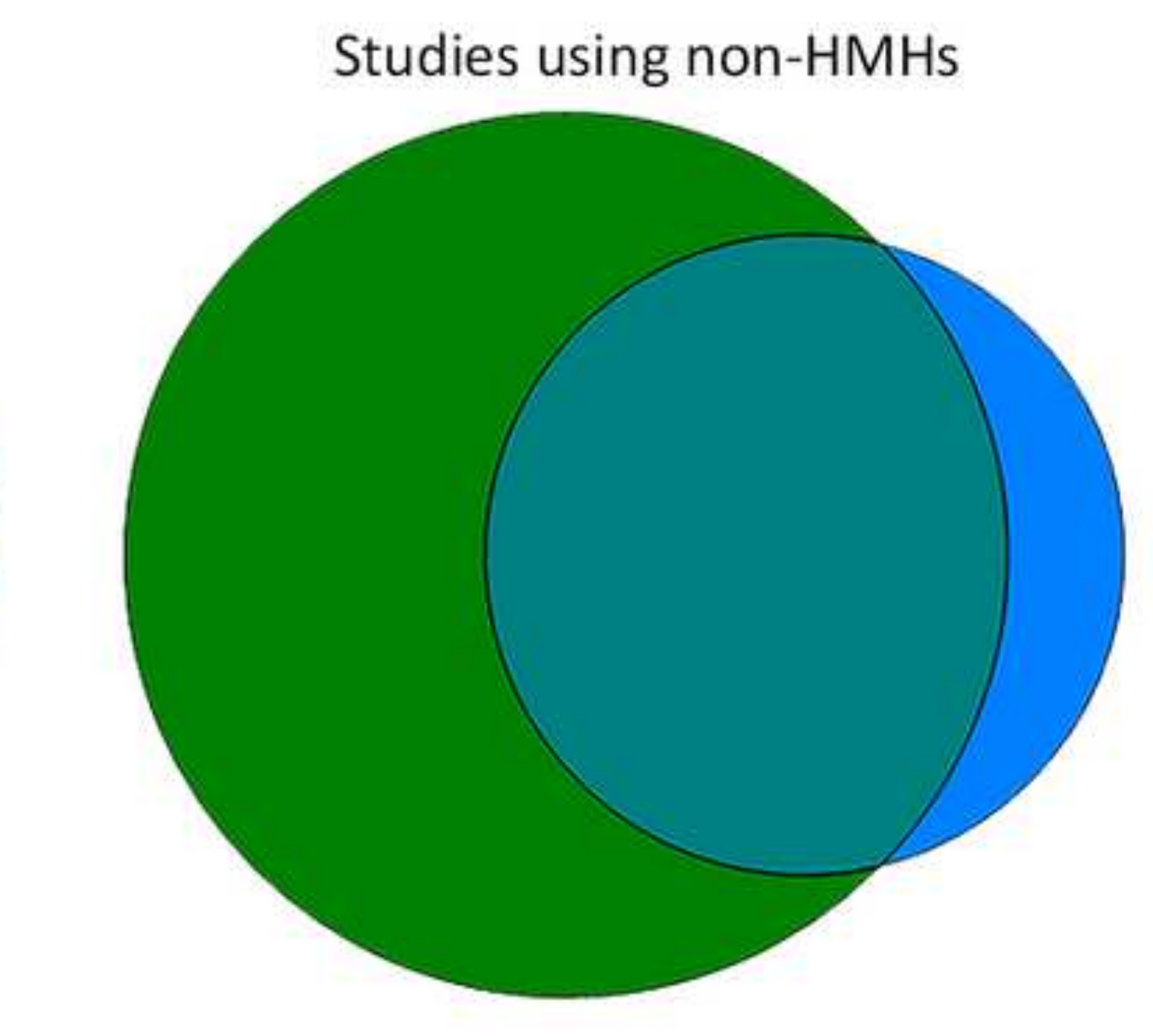


a Rate of heavy metal extraction (mg/day)

- Total heavy metal extracted (mg)

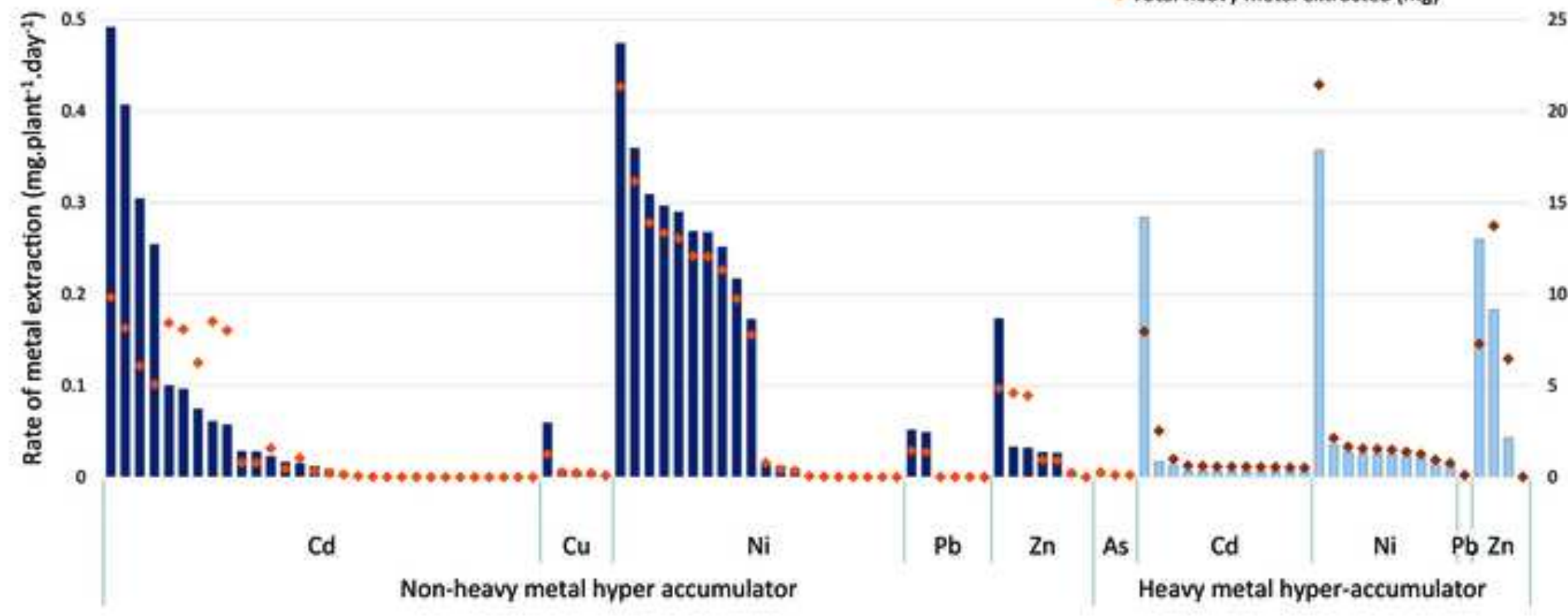

